\title{
La herencia cultural latinoamericana como poética docente
}

\author{
Matías Marcipar \\ [Universidad Nacional del Litoral]
}

\begin{abstract}
Resumen Las prácticas docentes están sostenidas en poéticas, cuales narraciones, dan sentido a la enseñanza y proveen criterios para la selección de contenidos. La MPL (Música Popular Latinoamericana) tiene su presencia en los textos curriculares, pero su devenir curricular depende en gran medida de quienes estén movilizados por una poética de lo latinoamericano en la educación. A su vez, el concepto mismo de una poética docente que busque dar vida a la herencia cultural latinoamericana presenta un enorme margen de ambigüedad. Desde el contexto concreto y experiencia de la secundaria especializada en música popular en vivo CREI, el artículo intenta problematizar el asunto en sus distintas aristas, proponiendo un breve repaso histórico por roles institucionales y posicionamientos político-educativos en relación a la cultura.
\end{abstract}

Summary Teaching practices are sustained in poetics, which narrations give meaning to teaching and provide criteria for the selection of content. The MPL (Latin American Popular Music) has its presence in curricular texts, but its curricular evolution largely depends on those who are mobilized by a Latin American poetics in education. In turn, the very concept of a teaching poetic that seeks to give life to the Latin American cultural heritage presents an enormous margin of ambiguity. From the concrete context and experience of the CREI secondary school specializing in live popular music, the article tries to problematize the issue in its different edges, proposing a brief historical review of institutional roles and political-educational positions in relation to culture.

\footnotetext{
* Este artículo está basado en el trabajo final para el seminario de postgrado "La música incaica y la imaginación histórica en la musicología sobre los Andes" dictado por el Dr. Julio Mendívil.
} 


\section{INTRODUCCIón}

¿Qué valor damos a la presencia curricular de la Música Popular Latinoamericana en estos tiempos anti-esencialistas? ¿Cuán en serio deberían ser tomados estos contenidos? ¿Qué sentidos les damos? Partiendo de estos interrogantes, vamos a proponer algunas reflexiones desde ciertas prácticas con ciertos géneros, ciertos orgánicos y ciertos repertorios en tiempos de hyperculturalidad (Han, 20r8), en donde pareciera que nada debiera ser canónico, porque cualquier cosa podría serlo, y porque lo que podría ser para unos no lo sería para otros, despojando así a todo recurso e insumo para el aula de algún carácter social trascendente. Pero así como no sólo se enseña música en las escuelas "porque es lindo» sino porque además es formativo, creemos en razones más allá de la lindura (aunque vaya si la tiene para nosotros) para escoger y priorizar ciertos contenidos que tienen que ver con la MPL, frente a otros contenidos posibles. Se nos ha repetido que los esencialismos suelen terminar siempre en algún tipo de cruzada o guerra santa, desde la adhesión a lógicas binarias del tipo «bondad/maldad» y su variante "pureza/impureza». Bien: abolidos los relatos esencialistas, ¿qué relatos los reemplazan? Seguramente aquellos que sostengan el gusto del docente de turno -lo cual no es en sí algo malo-, vinculado ineludiblemente a su trayecto afectivo-emocional. Hoy existen consensos en aceptar y naturalizar esta situación. El problema es que el emocionalismo ${ }^{1}$ nos queda corto (no nos sirve en verdad) para nuestro objeto, que es el currículum como constructo y resultado de intereses en puja (De Alba, I99I). Y si bien no queremos emprender ninguna guerra santa, nos encantaría que la industria cultural deje de triturar la diversidad y de reducir la oferta simbólica al hit de cada verano, o a los hits del verano destinados a cada target social. Como la industria cultural no dejará de hacerlo, consideramos que algún rol tenemos los docentes en este juego, algún necesario contrapoder está en nuestras manos. Además, de que el gusto no tiene nada de neutral, inocuo ni azaroso, como ya lo analizaba Bourdieu$^{2}$, por lo que debería ser asunto importante en los profesorados, al menos, cultivar cierto espíritu crítico respecto del gusto, junto con cierta sospecha por lo mainstream.

1 "La "emocionología" parece haber tomado el lugar de la ideología. Un estado de cosas en el cual vuelve a plantearse una vieja pregunta con nuevos matices: si este giro emocional supone un capitalismo más humano, de mayor sensibilidad o se trata, una vez más, del apogeo del individualismo y de la cultura del hedonismo" (Arfuch, 2018, 17) 2 Bourdieu, P. (2018). El sentido social del gusto. Siglo XXI. Buenos Aires. 
La «música popular latinoamericana» es un constructo al que adherimos, siendo conscientes de que es una abstracción que en lo práctico remite a las significaciones más dispares, como ya hemos observado en otras publicaciones ${ }^{3}$ (y que en cuestión de gustos, puede contener y nombrar a «todo y su contrario»). ¿Qué hacemos con este significante flotante?¿Qué uso podremos darle?

En su experiencia histórica, el latino-americanismo ha buscado re-inyectar saberes populares desde las estructuras formales educativas. Estos intentos también pueden ser discutibles, junto con la pregunta de De Certeau sobre si lo popular existe más allá del gesto que lo suprime, y junto con esta, otra pregunta poco simpática pero necesaria: ¿Lo popular, es realmente estimulado por la enseñanza de lo popular desde las instituciones? Lo popular, entendido no como tal o cual repertorio sino como el poder creativo de nombrarnos con nuestras propias palabras y sonidos, haciendo uso del ejercicio de la elección en toda su complejidad, independientemente de nuestra condición de clase, o incluso, mejor, asumiéndola. Hemos dicho en otra publicación ${ }^{4}$ que somos conscientes de que en nuestras prácticas estamos muchas veces más «inventando» que "rescatando», pero desde fuentes inspiradoras, y que esas creaciones se remiten a sus fuentes, que a su vez provienen de otras. Rizomas más que raíz, transformaciones permanentes, transculturaciones, sí, pero en función de un nosotros y de un territorio donde estamos y necesitamos convivir. Y como decíamos, más experiencia que esencia, sí, pero experiencia precisamente del sujeto histórico de dicho territorio inabarcable, diverso y caótico, pero con tanto en común. Experiencias de prácticas musicales que poco tienen que ver con la industria cultural ${ }^{5}$, a pesar de lo que ella pueda abducirles, y a pesar de lo que ella pueda encorsetarlas. Experiencias que se constituyen en nuevos constructos, nuevos rizomas al entrar al aula dando lugar, desde cierta poética docente, a prácticas que buscan el empoderamiento cultural y ciudadano. Esa poética es la que intentará expresarse en el presente artículo.

\footnotetext{
3 Publicación Sonamos Latinoamérica $n^{\circ} .1$

4 Actas Músicos en congreso, 2019.

5 La industria cultural es otro asunto de debate que excede el presente artículo. En las últimas décadas, los propios estados y desde todos los colores partidarios imaginables han desarrollado sus políticas para el desarrollo de "la industria cultural", desde una idea de que toda la cultura ha adquirido el formato industrial. Nosotros cuestionamos esto: se puede hacer contra-hegemonía con las mismas herramientas de la hegemonía y obtener... ¿̇resultados diferentes? No lo creemos.
} 


\title{
INSTRUMENTOS NATIVOS Y RÍTMICAS POPULARES EN EL CURRÍCULUM: EL CASO DE LA ESCUELA «CREI»
}

En septiembre de 2017 presentábamos, junto a colegas del CREI $^{6}$ y en el marco de «Músicos en Congreso» (MEC) un panel en donde señalábamos, desde lo que Freire llama contexto concreto, un tipo de práctica docente que hemos nombrado como didáctica de la oralidad. En ella la transmisión de la herencia cultural latinoamericana se erige en poética docente, y así lo expresábamos:

\begin{abstract}
[...] giramos en torno a una poética de lo latinoamericano y sus repertorios vinculantes. Dentro de esto, debemos asumir el compromiso de entender sus construcciones y contradicciones, prefiriendo siempre lo desconocido a lo mediático y/o lo masivo. [...] el patrimonio no es ya identidad sino mediación hacia ella. Es herencia, pero que no se hereda sino que se conquista. Es la responsabilidad de mantener el fuego, y no la adoración de cenizas. Es el intento de visualizar raíces, desde las cuales podemos redefinirnos. (Actas Músicos en congreso, 2019: 150)
\end{abstract}

Nótese el controversial término patrimonio, examinaremos más adelante este asunto. Por lo pronto, el enunciado retoma un constructo del manifiesto del Encuentro de música popular de Rosario ${ }^{7}$ : práctica de lo popular frente a lo masivo mediático. Este antagonismo popular versus mainstream es una construcción narrativa que podría presentar muchísimas discusiones conceptuales pero que defendemos porque afirma, como contrapeso, el rol de lo público frente al avasallamiento del mercado.

En los textos curriculares de "CREI-Secundaria» ${ }^{8}$ aparecen las asignaturas INS y RIPL (Instrumentos Nativos Sudamericanos - Rítmica e instrumentos populares latinoamericanos) proponiendo a lo largo de los cinco años de trayecto, un espacio curricular dedicado plenamente a las músicas latinoamericanas de raíz tradicional, asignaturas de dos horas reloj de práctica semanal. Desde el cuantioso repertorio disponible se abordan rítmicas y géneros, junto con el conocimiento y la práctica de variedad de instrumentos llamados autóc-

6 "CREl" (cuya sigla es la abreviatura de Centro recreativo estético infantil) es una de las escuelas de música de la provincia de Santa Fe, que desde 2013 alberga una la secundaria musical, proyecto educativo al que nos estamos refiriendo en el presente trabajo. Comparte textos curriculares con la escuela Nigelia Soria de la ciudad de Rosario.

7 Disponible en el sitio del encuentro: http://www.encuentrodemusicos.com/quienes-somos/fundamentos

8 Los textos curriculares del secundario artístico santafesino pueden consultarse en: http://www.pearltrees.com/ secundarioartistico 
tonos y criollos, observando también los particulares usos de instrumentos de origen europeo sin modificaciones en su lutería pero convertidos en otro instrumento por el tipo de uso. Desde este contexto concreto es que pensamos y escribimos. Hagamos ahora un poco de historia.

\section{¿RESCATAR? ¿PRESERVAR? NACIONALISMOS Y LATINOAMERICANISMOS}

De fuerte presencia en el siglo xx, nacionalismos y latinoamericanismos se ocuparon de las músicas populares. Previo a ellos, la hegemonía era la del canon colonial, en donde «compositor» era el que había estudiado en Europa ${ }^{9}$, y todo lo que fuese "cosa de indios» y/o "cosa de negros» no entraba en la categoría de la "cultura» ${ }^{10}$. Este dominio fue sacudido, de la mano de nacionalismos y latinoamericanismos - con sus matices y sus contradicciones internas -, por cierta idea de rescate cultural. El nacionalismo desde una idea de esencia nacional sustentada en lo puro y recóndito del mundo campesino haciendo de él una estampa estática e incontaminada; y el latinoamericanismo, ya más desde posturas nativistas como la de J. M. Arguedas, buscando tender puentes con las otredades cercanas, como fue por ejemplo el proyecto cultural de la up en Chile, o de modo muy diferente la actividad teórica de Coriún Aharonián desde Uruguay.

En su devenir histórico, ambas corrientes propusieron nuevos cánones culturales, y su lucha llega a dos territorios claves: el museo y el currículum. Y cuando decimos museo incluimos aquí a las salas de concierto, quienes asumieron la función del museo para las expresiones sonoras.

Las pujas resultantes entre residuales europeísmos, arcaicos nacionalismos, nuevos latinoamericanismos, emergentes posmodernismos, pos-colonialismos,

\footnotetext{
9 Carlos Vega escribió en su tiempo que «vivimos de europa, su pensar y su sentir nos encantan. Acodados en el puerto, de espaldas al país, esperamos la última palabra de los pensadores, literatos y artistas de ultramar, con impaciencia de novios. Sin fe en nosotros mismos, sin esperanza en nuestro esfuerzo, estamos alimentando uno de los grandes factores internos de nuestra esterilidad"... (citado en "Conversaciones sobre música, cultura e identidad" de Coriún Aharonián). Esta realidad histórica produjo muchas dinámicas propias de nuestro continente. En un trabajo anterior, habíamos observado, desde categorías propuestas por el compositor Dante Grela, que: "Desde una perspectiva histórica, la linealidad evolutiva que se da en la endogámica historia musical europea no puede finalmente replicarse en el nuevo continente: los desarrollos propios desde "semillas" europeas fruto del aislamiento americano, son sistemáticamente interrumpidos por las actualizaciones de los cánones compositivos que, intermitentemente, van llegando, desde Europa. La construcción del nuevo continente como réplica, tiene su punto ciego en la imposibilidad, por subordinación absoluta, de replicar la linealidad: las linealidades emergentes de la periferia colonial son truncadas por las actualizaciones del centro referencial.» (Marcipar, 2015: 7).

10 Kush propone en este punto, como clave de comprensión, el eje hedor/pulcritud. Las distintas corriente decolonialistas y pos-colonialistas abordarán este tema clave del área. (Aharonián, Farías Gonzalez, etc.).
} 
multiculturalismos, etc; como sistemas de contradicciones, como ensaladas dialécticas, o, como se la nombra en el campo del currículum, como síntesis cultural (De Alba, I99I), son, finalmente, así, en amasijo, herencia. ¿Qué haremos con todo esto? ¿Con qué nos quedamos? ¿Hay que rescatar? ¿Hay que preservar? El rescate y la preservación implican la acción de jerarquizar, algo resistido en tiempos de corrección política posmoderna multiculturalista. ¿Y entonces qué? ¿Le regalamos esta acción a los algoritmos?, es decir, ¿a los intereses de quienes los diseñan?

\section{Museo y CURRículum}

Territorios de disputas en relación a las hegemonías culturales, museos y currículum tienen en común el presentar una selección de lo que «merece» ser puesto en relieve, estableciendo cánones y jerarquías. Como afirmó Michel Foucault, allí donde está lo más aparentemente neutral de las instituciones, lo incuestionable, lo permanente, allí está lo más ideológico, lo que más debe ser cuestionado por la labor intelectual ${ }^{11}$. La falsa neutralidad de estas dos instituciones, museo y currículum, se evidenciaba ya hace alrededor de roo años, cuando en paralelo ya se estaban dando dos debates: por un lado entre los textos de Dewey y Bobbit para el campo del currículum; y, por otro, desde las embestidas que dadaístas y futuristas daban a la institución museo. Escribe Furlán que:

\footnotetext{
Mientras que Dewey subrayaba la necesidad de que la escuela sea una promotora de experiencias de cultura democrática, Bobbit subrayaba la necesidad de que la escuela sea una favorecedora de la producción de aprendizajes
}

11 Dice exactamente Michel Foucault: "Tenemos la costumbre, al menos en nuestra sociedad europea, de creer que el poder está en manos del gobierno y que es ejercido por unas instituciones muy particulares, que son la administración -en Francia le llamamos prefectura-, la policía, el ejército, instituciones concebidas para hacer obedecer y castigar aquellos que desobedecen. Pero yo creo que el poder político se ejecuta, todavía y mucho más, a través de una cierta cantidad de instituciones que parecen no tener nada en común con el poder político, que parecen ser independientes y que no lo son. Sabemos bien que la universidad y de manera general todo el sistema escolar, que en apariencia fue creado para distribuir conocimiento, cumple el rol de mantener en el poder cierta clase social y excluir de los instrumentos del poder a todas las demás. Algo como la psiquiatría, que en apariencia está destinada al bien de la humanidad y al conocimiento psiquiátrico, es otra forma más de hacer pesar cierto poder político sobre un grupo social. Igualmente la justicia. Me parece entonces que la tarea política actual en una sociedad como la nuestra es la de criticar el juego de aquellas instituciones en apariencia más neutrales e independientes, atacándolas de tal manera que la violencia política que oscuramente se ejerce en ellas se visibilice para que podamos luchar contra ellas. (Facebook Podemos Paris, posteo de Mayo 2017, consultado y desgrabado el 25/4/2018) 
útiles en función de las características de los medios en los cuales los egresados se insertan. (Furlán, 1997: 5)

En lo referido a la educación artística, Dewey ${ }^{12}$ le daba un lugar especial a la educación artística en la idea de promoción de ciudadanía, (y más adelante, Freire, desde América Latina, hablará de empoderamiento), mientras que el utilitarismo de Bobbit remite lo cultural a lo estrictamente simbólico funcional para la identificación, es decir, como transmisión del relato necesario a la cohesión nacional ${ }^{13}$. Este debate fundacional es el punto de partida de una genealogía de discusiones, en donde el lugar del arte en el currículum irá teniendo a lo largo de los siglos xx y xxI, distintas concepciones y versiones. En El arte y la creación de la mente Elliot Eisner enumera muchos de sus tópicos: enseñanza del arte basada en las disciplinas, cultura visual-musical, resolución creativa de problemas, expresión personal creativa, la educación artística como preparación para el mundo laboral, las artes y el desarrollo cognitivo, el uso de las artes para mejorar el rendimiento escolar, artes integradas, y lo que decanta de esto, es la inevitable cuestión de clases sociales ya analizada por Bourdieu y Passeron (1964) en $\operatorname{Los}_{\text {herederos }}{ }^{14}$ : el tiempo libre, la estimulación de la imaginación y los espacios para el arte, son parte esencial del marco de formación de los herederos del poder. Ivor Goodson a su vez trata este asunto en su Historia del curriculum ${ }^{15}$. Una y otra vez, aparece la relación entre arte y poder, con el arte que empodera, el poder que necesita del arte y que a su vez le teme, y que por tanto, como bien plantea Imanol Aguirre (20I4), prefiere dosificarlo, encor-

12 Es interesante resaltar que el propio Dewey fue un gran impulsor de la educación artística en cuanto empoderadora social, pero que esta idea de empoderamiento queda siempre dentro de una poética de la educación general, y que en los sitios de formación para el arte (que en el caso de la música tiene su matriz en los conservatorios fundados por la revolución francesa) la visión tecnicista tiene mucho más que ver con lo defendido por Bobbit. El resultado en nuestra área es que la clase de música en la educación general es en los hechos y funcionalmente un momento recreativo, mientras que en conservatorios y escuelas de música, la formación de instrumentistas, intérpretes, directores y compositores demandan el mismo temple que requiere un estudiante de ingeniería. La educación general no debiera perder de vista cuán empoderante es la técnica, porque es ella, junto al uso que se haga de ella, quien brinda las herramientas de los lenguajes.

13 En esta línea podemos ubicar al caso del llamado Folklore argentino, como construcción de los nacionalismos, a partir de las manifestaciones populares campesinas. De su mano, se tornaron hegemónicas y por ende, paradigma. Como bien lo de-construye Oscar Chamosa (2010), la "invención del folklore argentino" ha sido una herramienta de proselitismo y de unidad del sentido de pertenencia, construido desde políticas de estado.

14 Bourdieu, P.; Passeron, J. C. (1964) Los herederos. Los estudiantes y la cultura. Siglo veintiuno editores, 3ra ed.-2013-. Buenos Aires.

15 Goodson, I. (1995). Historia del currículum. La construcción social de las disciplinas escolares. Pomares-Corredor. Barcelona. 
setarlo, a través de dosificar y encorsetar su medio de reproducción: la educación artística. Lo cierto, es que como lo describe Alicia de Alba (I99I):

Por currículum se entiende a la sintesis de elementos culturales (conocimientos, valores, costumbres, creencias, hábitos) que conforman una propuesta políticoeducativa pensada e impulsada por diversos grupos y sectores sociales cuyos intereses son diversos y contradictorios, aunque algunos tienden a ser dominantes o hegemónicos y otros tiendan a oponerse y resistirse a tal dominación o hegemonía. Síntesis a la cual se arriba a través de diversos mecanismos de negociación e imposición social. Propuesta conformada por aspectos estructurales-formales y procesales-prácticos, así como por dimensiones generales y particulares que interactúan en el devenir de los currículum en las instituciones sociales educativas. Devenir curricular cuyo carácter es profundamente histórico y no mecánico y lineal. Estructura y devenir que se conforman y se expresan a través de distintos niveles de significación. (De Alba, I99ı: 38-39)

Los proyectos curriculares son entonces, una cristalización de un momento determinado de pujas de poder, de una dialéctica, en el que "lo cultural patrimonial», y/o "la herencia cultural» son manifestaciones de los más variados posicionamientos europeístas, nacionalistas, latinoamericanistas, neo-liberales y posmodernos, en un mix de culturas arcaicas, residuales y emergentes ${ }^{16}$, cada una tratando de educar en una manera de ver, y por ende, también de no ver (Eisner, 20i6).

En cuanto a los cánones artísticos para el currículum, es precisamente el museo quien provee los insumos. Pero este a su vez, comienza a ser cuestionado, aproximadamente en los mismos tiempos históricos (principios del siglo $\mathrm{xx})$, tal como lo describe Boris Groys:

A comienzos del siglo $\mathrm{xx}$, los artistas y escritores de vanguardia comenzaron una campaña contra los museos, y, de manera más general, contra la preservación del arte perteneciente al pasado. Formularon una pregunta sencilla: ¿Por qué se privilegian ciertas cosas, porqué la sociedad se preocupa por ellas e invierte dinero en su conservación y restauración, mientras que se dejan otras cosas libradas al poder destructor del tiempo, y a nadie le importa que eventualmente desaparezcan? Las respuestas tradicionales a esta cuestión ya no se

16 Categorías R. Williams, retomadas por M. Barbero en BARBERO, J. M. (1987). De los medios a las mediaciones. Comunicación, cultura y hegemonía. Ediciones G. Gilli. México. 
consideraban satisfactorias. Marinetti proclamó, entonces que las estatuas de la antigua Grecia no eran más bellas que un coche moderno o un avión. ¿Podemos afirmar que nuestro propio valor es menor al de la gente que vivió antes? La polémica de la vanguardia contra la institución del museo estaba inspirada por el mismo impulso igualitario y democrático que mueve a la política moderna. Sostenía la igualdad de las cosas, los lugares y, lo que es más importante, los tiempos de un modo similar al que se sostiene la igualdad entre los hombres. (Groys, 20I6: 6)

El canon se exponía en museos y se enseñaba en las escuelas. Lo escribimos en tiempo pasado porque estas características de la organización social de la modernidad son hoy una realidad perimida: hoy el canon pareciera ser reemplazado por un set caótico de referencias brindado-ni gratuito, ni inocentemente- por internet.

La cuestión es que como bien recuerda Groys, los museos fueron, durante la modernidad, "la institución que definía el régimen dominante bajo el cual funcionaba el arte»(Groys, 20I4: 133). Como ya lo hemos sugerido, para la música, este fue el lugar de los teatros a la italiana que se replicaron a lo largo y ancho de todo el continente. Aún hoy, a modo de persistencia cultural arcaica, los repertorios de las orquestas sinfónicas estatales sostienen año tras año y más allá de ciertas aperturas, el mismo puñado de obras clásicas, afirmando el pedestal de la gran música ${ }^{17}$. La cuestión entonces, es que el museo fue el encargado de sostener un patrimonio y el currículum, el encargado de transmitirlo como herencia. El museo en relación a la preservación de materiales, así como el currículum en relación a la preservación de saberes.

\section{¿PATRIMONIO? ¿HERENCIA?}

Hoy día, en que la noción de lo popular está instalada en las instituciones, «lo latinoamericano» (con todo lo impreciso del término) es un componente ineludible. Pero, ¿Para qué queremos en el sistema educativo estos contenidos, esas prácticas, que además tuvieron historias canónicas paralelas a la de las instituciones y con lógicas diferentes, y cuyos esfuerzos de academización no aseguran necesariamente su transmisión? ¿Por qué consideramos a estas prácticas y

17 Como plantea Julio Mendívil En Contra la música, es claro que cuando se habla de «la música» se excluyen «las músicas". 
repertorios como patrimonio? ¿Es nuestra identidad o acaso estamos forzando un proceso de identificación ${ }^{18}$ ? ¿Porqué queremos tomar como herencia a este patrimonio? Pero hay más: ¿Porqué muchas veces el término patrimonio es resistido y reemplazado por herencia? Patrimonio y herencia, ¿son una misma cosa? La tensión entre estos dos términos vuelve una y otra vez, cuando queremos expresar el por qué de nuestra démarche educativa. A veces se utilizan como sinónimos, cuando sin embargo, también pueden ser hasta antagónicos. ¿Podrán ser complementarios? ¿Conviene?

Ambos términos nunca faltan en las secciones curriculares abocadas al arte y la cultura. Como vimos, el proyecto curricular es siempre una selección, lo que implica una reflexión sobre lo «importante», apareciendo junto con esta la noción de lo «jerárquico»: no da lo mismo enseñar una cosa que otra, y la acción de elegir, supone obviamente que lo elegido es más importante que lo no elegido. Pero además inevitable no poder darlo todo en un trayecto por la obvia razón de que los tiempos no son infinitos, lo que implica, - más allá de toda ideología y por sentido común -, una selección. Lo «patrimonial» suele ser un criterio. O una excusa. A su vez "patrimonio» está connotado de patriarcado y esencialismos, entre muchas más cosas. En relación a los contenidos que nos ocupan, tendemos a pensar que la inclusión de los repertorios latinoamericanos en el currículum hace justicia a un "patrimonio» o a una «herencia». Este pensamiento tiene, como ya mencionamos, una impronta salvadora y misionera, como poética de rescate cultural que sostiene nuestro cotidiano docente. Y allí, cierto esencialismo se erige, inevitablemente. ¿Es esto un problema? ¿Debemos a toda costa huir de los esencialismos? ¿No será el anti-esencialismo otra forma de esencialismo finalmente?

En este asunto del patrimonio a resguardar, se presenta además una paradoja: como bien describe Byung Chul-Han en Shanzai (20I4), sostener, conservar los monumentos históricos que nos dan el testimonio de un pasado fundante, de una esencia, implica un esfuerzo sostenido de mantenimiento y reconstrucción permanente, poniendo en obra todos los recursos existentes y por desa-

18 Esta pregunta se vuelve aún más inquietante a través de las claves que Brinda Héctor Díaz Polanco: "A diferencia de la identidad, la identificación nace en el seno mismo del sistema globalizador y este no encuentra mayor dificultad para integrarla en su lógica. La identificación es un sucedáneo de lo colectivo, regularmente inocuo para el sistema globalizante e individualizador. Al no superar la individualización, la identificación crea la ilusión de una comunidad salvadora; o, si se quiere, crea una comunidad en el marco de la lógica global o un conglomerado ya globalizado para cualquier efecto. El sistema globalizado proporciona los elementos y las condiciones que hacen posible esa "comunidad». De hecho los que tejen la identificación están realmente subsumidos en la lógica globalizadora de la que quieren escapar, y de este modo la alimentan. (Díaz Polanco, 2015: 31) 
rrollar para hacer frente a la degradación inevitable de un ícono que debe verse como inmortal. Esta es la paradoja misma del conservadurismo: la lucha perdida de antemano por sostener lo que en teoría se sostiene por sí solo. Pero en la idea de patrimonio está también el hecho de que debemos sostenerlo porque él a su vez nos sostiene. Como un pasado, un hecho fundante que marca las invariables de nuestra existencia, debemos sostener el patrimonio para no morir con él. Casi como algo que nos eligió a nosotros y de cuya vida depende la nuestra. Esta idea confronta con la de Jaques Derrida, para quién, la herencia es algo que se escoge, para quién, la herencia es una construcción personal. No hay herencia sin proceso de elección, adopción de lo elegido, e, inevitablemente, su reconfiguración. En sus conversaciones con Derrida, Elizabeth Roudinesco expresa que:

[...] la mejor manera de serle fiel a una herencia es serle infiel, es decir, no recibirla literalmente, como una totalidad, sino más bien pescarla en falta, captar su «momento dogmático»: «yo me siento heredero, fiel, en la medida de lo posible". (Derrida-Roudinesco, 20I4: IO)

A lo que Derrida responde:

[...] siempre me reconocí, ya se trate de la vida o del trabajo del pensamiento, en la figura del heredero, y cada vez más, de manera cada vez más asumida, con frecuencia feliz. Al explicarme de manera insistente sobre ese concepto o esa figura del legatario, llegué a pensar que, lejos de una comodidad garantizada que se asocia un poco rápido a dicha palabra, el heredero siempre debía responder a una suerte de doble exhortación, a una asignación contradictoria: primero hay que saber, y saber reafirmar lo que viene "antes de nosotros», y que por tanto recibimos antes incluso de elegirlo, comportarnos al respecto como sujetos libres. Sí, es preciso (y ese es preciso está inscripto en la propia herencia recibida); es preciso hacerlo todo para apropiarse de un pasado que en el fondo permanece inapropiable, ya se trate de memoria filosófica, de la precedencia de una lengua, de una cultura, y de la filiación en general. ¿Qué quiere decir reafirmar? No sólo aceptar dicha herencia sino reactivarla de otro modo y mantenerla con vida. No escogerla (porque lo que caracteriza la herencia ante todo es que no se la elije, es ella la que nos elije violentamente), sino escoger conservarla en vida. En el fondo, la vida, el ser-en-vida, se define acaso 
por esa tensión interna de la herencia, por esa reinterpretación de la circunstancia del don, hasta de la filiación. (Derrida-Roudinesco, 20I4: I2)

En síntesis: «Un heredero no es solamente alguien que recibe, es alguien que escoge y que se pone a prueba decidiendo» (Derrida-Roudinesco, 20I4: I6)

Ahora bien: esto que es tan claro en la dimensión sujeto, ¿̨podrá pensarse para lo colectivo desde las mismas lógicas, en una especie de correspondencia fractal ${ }^{19}$ elemento/totalidad, -como lo plantea el paradigma de la complejidad? Es decir: los colectivos, ¿escogen su herencia simbólica al igual que los sujetos? ¿Son aplicables estos preceptos de J. Derrida a lo social? Y en tal caso ¿qué rol jugamos en esto desde las instituciones educativas?

\section{HERENCIA Y EXPERIENCIA}

Cuando nada ha ocurrido aún, desde la posibilidad total, desde la hoja en blanco de lo que aún no fue, y sólo en esa instancia, todo es posible, al menos en teoría. Pero una vez que hemos vivido, fuimos algo, y la experiencia nos ancló en una identidad, que no es verdad ni verdad, no es esencia ni no esencia, es nuestra vida. Toda construcción narrativa puede iniciarse creativamente como especulación mental, pero luego, si persiste, se enreda en la experiencia, y entonces lo vivido nos constituye. El folklore por ejemplo, pudo haber sido una invención, pero fue luego la vida de cientos de miles, que además ensancharon con su práctica modos, usos y repertorios, que constituyen extensos recursos para la escuela.

Pero hay más: el contagio de la curiosidad, el gusto por la precisión, la obsesión por la colección de informaciones, sólo entran en circulación cuando es sentida como verdad por quien está en el rol docente. Hay que estar motivado para ser motivador, e invirtiendo el frecuente concepto de perdida de sentido, hablemos de una ganancia de sentido de quien puede sostener el deseo de enseñar. Y entonces podríamos retomar, al menos funcionalmente, la idea de la herencia y el patrimonio como aquellas cosas que debemos sostener porque ellas nos sostienen. El concepto, obvio y trillado, no deja de ser un buen concepto, cuando de todas maneras un docente de arte comparte pasiones, y en verdad no sólo un docente de arte. Por fuera de nuestra existencia biológica, no

19 El principio del fractal es uno de los siete principios del paradigma de la complejidad propuesto por E. Morin. 
somos otra cosa que construcciones narrativas que van condicionando nuestras percepciones a lo largo de nuestra experiencia vital, sedimentando conocimientos anclados además en matrices emocionales (Silberstein, 2005). Como señalaron Derrida y Roudinesco, escoger su herencia implica procesos sensibles y racionales. No hay herencia sin reflexión, sin trabajo de autoconocimiento, sin indagatorias interiores, sin diálogo con lo disponible como herencia.

Como músicos y docentes, el desafío es este mismo trabajo sobre la herencia pero en lo colectivo, en donde, creemos, debiera sostenerse alguna trinchera ante el infierno de lo igual, y ante el multiculturalismo consensual (Díaz Polanco, 2015) porque se trata del rol del estado frente a la aplanadora del mercado, en tiempos de neoliberalismo y capitalismo especulativo. Y especialmente como docentes, no estamos parados en cualquier lugar en relación a este asunto.

Como dispositivo del estado, como escuela pública, debemos también poder articular con entidades de la sociedad civil, en donde muchas asociaciones y colectivos sostienen patrimonios que permiten a las minorías sostener sus necesarios relatos. Las comunidades de extranjeros organizadas en personerías jurídicas son un ejemplo de esto.

Los sapiens ${ }^{20}$ nos heredamos básicamente capital simbólico, al que canonizamos como patrimonio. "Nada más natural que esta artificialidad humana», que además, en sus aspectos prácticos, es óptimamente eficaz cuando es aprendida, percibida y sentida como esencia. En nuestros nacionalismos, europeísmos, latinoamericanismos y anti-esencialismos, finalmente, somos tan vulgarmente sapiens que no escapamos a la normalidad más absoluta de la especie.

Por ello, desde nuestra poética docente (Silberstein, 2005), abrazamos nuestros instrumentos nativos latinoamericanos que escogemos como herencia, que nos permiten encontrarnos con otras subjetividades, hermanándonos con otras vidas y experiencias a través de la sensibilidad por ciertas materidades sonoras. Hemos pasado la vida cargando un peso que nos dio identidad, y lo volvemos a elegir. Llevando instrumentos de aquí para allá, como un ekeko, sosteniendo esa imagen antojadiza del músico con un charango, un sikus, un

$20 \mathrm{Si}$ algo nos caracteriza como humanos, en cuanto a especie, es precisamente, el fenómeno de los imaginarios e identidades colectivas. El historiador Yuval Noah Harari (2015), sostiene que la característica fundante del sapiens es su capacidad de instalar estos imaginarios colectivos en miras a la suma de voluntades que permitan alcanzar objetivos que, en soledad y siendo él limitado físicamente, no hubiera alcanzado jamás. En ese sentido y según el mismo autor, no hay diferencia entre el espíritu tutelar del ciervo para un cavernícola de la revolución cognitiva (70.000 AP); y el capitalismo del sapiens actual. Este aspecto "pragmático" y utilitario, es la principal razón de ser del imaginario colectivo en el sistema del sapiens. Movilizar la sociedad hacia tareas comunes, dando un sentido vital a las individualidades, a través de lo que se comparte. 
cuatro, un tiple, una quena, una huancara, un cabaquiño, un repique de candombe, y una gaita colombiana, redefiniendo estéticas en donde el groove es materia prima y el sentido de identidad, contención.

\section{Bibliografía}

Aguirre, I., Pimentel, L., Jimenez, L. (2014). Educación artística, cultura y ciudadanía. Madrid: Fundación Santillana

Aharonián, C. (1992).Conversaciones sobre música, cultura e identidad. Montevideo: Ombú

Arfuch, L. (2018). La vida narrada. Memoria, subjetividad y política. Villa María: EDUVIM

Barbero, J. M. (1987). De los medios a las mediaciones. Comunicación, cultura y hegemonía. México: Ediciones G. Gilli

Benasayag, M. (2015). El cerebro aumentado, el hombre disminuido. Buenos Aires: Paidós

Bourdieu, P., Passeron, J. C. (2013) Los herederos. Los estudiantes y la cultura. Buenos Aires: Siglo veintiuno editores

Bourdieu, P. (2018). El sentido social del gusto. Buenos Aires: Siglo XXI

Chamosa, O. (2010). Breve historia del folklore argentino. (1920-1970). Identidad, política y nación. Buenos Aires: EDHASA

De Alba, A. (1991). Currículum: crisis, mito y perspectivas. México: UNAM

Derrida, J., Roudinesco, E. (2014). Y mañana, qué... Buenos Aires: Fondo de Cultura Económica

De Sousa Santos., B. (2010). Decolonizar el saber, reinventar el poder. Montevideo: Trilce

Díaz Polanco, H. (2015). El jardín de las identidades. La comunidad y el poder. Caracas: El perro y la rana

EIsner, E. (2016). El arte en la creación de la mente. Buenos Aires: Paidós

Freire, P. (2010). Cartas a quién pretende enseñar. Buenos Aires: Siglo XXI editores

Furlán, A. (1997). Currículum y condiciones institucionales. Conferencia en la Universidad autónoma de San Luis de Potosí.

Ginzburg, C. (2016). El queso y los gusanos. Ariel. Buenos Aires

Goodson, I. (1995). Historia del currículum. La construcción social de las disciplinas escolares. Barcelona: Pomares-Corredor

Gonzalez, J. P. (2013). Pensar la música desde América Latina.. Buenos Aires: Gourmet Musical Ediciones 
Groys, B. (2014). Volverse público. Buenos Aires: Caja negra editora (2016). Arte en flujo. Buenos Aires: Caja negra editora

Harari, Y. N. (2015). Sapiens. Paris: Albin Michel

Han, B.C. (2013). La sociedad de la Transparencia. Barcelona: Herder (2016). Shanzai. Buenos aires: Caja negra (2018). Hyperculturalidad. Barcelona: Herder

Kunn, T. (1971). La estructura de las revoluciones científicas. México: Fondo de Cultura Económica

Kush, R. (1962). América profunda. Rosario: Fundación Ross

López, María Inés; Reyna, Alejandro José ; Prendes, Marcia Natividad (comps.).(2019). Actas de Músicos en Congreso: Músicas latinoamericanas, perspectivas y enfoques en la educación. 6ta. edición, 2017. Santa Fe: Universidad Nacional del Litoral

Marcipar, M. (2015). Sombra europea, no linealidad e hibridación: persistencias históricas y características fundantes del presente musical latinoamericano. Trabajo final para el seminario Producción contemporánea en la música latinoamericana, Maestría en Educación Artística). UNR: Rosario

Mendívil, J. (2016). En contra de la música. Buenos Aires: Gourmet musical Morin, E. (2009). Introducción al pensamiento complejo. Barcelona: Gedisa Silberstein, F. (2005). Rorschach. Epistemología y lenguaje. Estructuración narrativa de la apercepción. Rosario: UNR editora

SILVA, L. (2013). Contracultura. Caracas: Fundarte

\section{RECURSOS ELECTRóNICOS}

http://www.encuentrodemusicos.com/quienes-somos/fundamentos

http://www.pearltrees.com/secundarioartistico

https://www.facebook.com/paris.podemos/videos/1203792366399041/

\section{Registro bibliográfico}

Matías MARCIPAR: "La herencia cultural latinoamericana como poética docente", en Revista del Instituto Superior de Música, número 17, Instituto Superior de Música, Santa Fe, UNL, República Argentina, 2020, pp. 107-121.

Descriptores / Describers

Patrimonio $\cdot$ herencia cultural $\cdot$ currículum 